RESEARCH REPORT

\title{
Urban area disadvantage and physical activity: a multilevel study in Melbourne, Australia
}

\author{
Anne M Kavanagh, Jane L Goller, Tania King, Damien Jolley, David Crawford, Gavin Turrell
}

J Epidemiol Community Health 2005;59:934-940. doi: 10.1136/jech.2005.035931

See end of article for authors' affiliations

.....................

Correspondence to:

Dr A M Kavanagh, Key

Centre for Women's

Health in Society,

University of Melbourne,

Melbourne 3010,

Australia; a.kavanagh@

unimelb.edu.au

Accepted for publication 3 June 2005
Objective: To estimate variation between small areas in the levels of walking, cycling, jogging, and swimming and overall physical activity and the importance of area level socioeconomic disadvantage in predicting physical activity participation.

Methods: All census collector districts (CCDs) in the 20 innermost local government areas in metropolitan Melbourne, Australia, were identified and ranked by the percentage of low income households $(<\$ 400 /$ week) living in the CCD. Fifty CCDs were randomly selected from the least, middle, and most disadvantaged septiles of the ranked CCDs and 2349 residents (58.7\% participation rate) participated in a cross sectional postal survey about physical activity. Multilevel logistic regression (adjusted for extrabinomial variation) was used to estimate area level variation in walking, cycling, jogging, and swimming and in overall physical activity participation, and the importance of area level socioeconomic disadvantage in predicting physical activity participation.

Results: There were significant variations between CCDs in all activities and in overall physical participation in age and sex adjusted models; however, after adjustment for individual SES (income, occupation, education) and area level socioeconomic disadvantage, significant differences remained only for walking $(p=0.004)$, cycling $(p=0.003)$, and swimming $(p=0.024)$. Living in the most socioeconomically disadvantaged areas was associated with a decreased likelihood of jogging and of having overall physical activity levels that were sufficiently active for health; these effects remained after adjustment for individual socioeconomic status (sufficiently active: OR $0.70,95 \% \mathrm{Cl} 0.55$ to 0.90 and jogging: $\mathrm{OR}=0.69,95 \% \mathrm{Cl} 0.51$ to 0.94 ).

Conclusion: These research findings support the need to focus on improving local environments to increase physical activity participation.
$\mathrm{P}$ hysical inactivity plays a substantial part in the development of coronary heart disease, non-insulin dependent diabetes, ischaemic stroke, and some cancers ${ }^{1}$ and is an important contributor to the total burden of disease in developed countries such as the USA, Canada, the UK, and

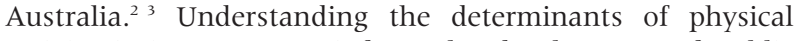
activity is important to inform the development of public health programmes aimed at increasing population levels of physical activity participation.

Most studies of the determinants of physical activity have focused on individual demographic characteristics such as individual socioeconomic status (SES), ${ }^{4-6}$ age, and sex. ${ }^{5}$ Recently researchers have argued that the environment in which people live may also be an important determinant of physical activity participation independent of individual characteristics and that health promotion activities may need to focus on improving local environments to encourage physical activity. ${ }^{78}$

International evidence regarding the importance of local environments for physical activity is relatively sparse. Positive associations have been reported between walking and living in high SES areas, ${ }^{9}$ residing in attractive areas, ${ }^{9-11}$ having convenient places to walk close to home, ${ }^{9-12}$ living near the coast. ${ }^{13}$ Propensity to walk has also been associated with living in neighbourhoods characterised by high residential density, land use mix (for example, residential, commercial, and parks), street connectivity, ${ }^{14}{ }^{15}$ good lighting, sidewalks, ${ }^{96}$ access to large, attractive public open spaces, trees, and minimal traffic. ${ }^{11}{ }^{17}$ Access to places to exercise and neighbourhood walking and cycling trails have been associated with increased overall physical activity levels. ${ }^{18}$
While the results of these studies are compelling, particularly with regard to the importance of the environment for walking, all have used single level analyses and have been unable to report the extent to which there is variation between areas in physical activity participation. Despite recent calls for the need for multilevel studies ${ }^{19}$ (studies that permit the estimation of fixed and random effects at the individual and area levels) these are less common; however, evidence to date suggests that living in areas that are socioeconomically disadvantaged is associated with lower overall levels of physical activity, even after adjustment for individual demographic variables including individual SES. ${ }^{2021}$

A recent multilevel study from the Netherlands found that residents living in the most socioeconomically disadvantaged areas were more likely to cycle or walk to the shops or work but were less likely to cycle, walk, or garden or participate in sporting activities in leisure time than residents of the least disadvantaged areas. ${ }^{22}$ Indeed that study showed that the reduced likelihood of participating in activities during leisure time was partly mediated by neighbourhood characteristics (rated by professionals in municipal authorities) including poorer physical design and the need for more police attention in the neighbourhoods. Other multilevel studies of walking and cycling in the Netherlands and USA have found that, after adjustment for individual demographic characteristics, increased walking is associated with the amount of sports grounds in residential areas, ${ }^{23}$ living in areas where a higher

Abbreviations: SES, socioeconomic status; CCD, census collector district 
proportion of residents have college degrees and, paradoxically, living in areas where a high proportion of residents live below the poverty line ${ }^{24}$; cycling has been associated with the square area of parks. ${ }^{23}$ None of these studies have reported information as to whether there was statistically significant variation in physical activity participation between areas.

In this paper we use a multilevel approach to estimate the small area variation in participation in overall physical activity and in four common physical activities: walking, cycling, swimming, and jogging. We then assess whether area level socioeconomic disadvantage has an impact on participation in the activities after individual differences between areas are taken into account. This is the first known study to assess area variation and the effect of area level socioeconomic disadvantage on a range of different physical activities.

\section{METHODS}

\section{Sample areas and population}

This cross sectional multilevel study was conducted in an area extending about 20 kilometres from the central business district in Melbourne, Australia. Melbourne is Australia's second most populous city, with a population of 3400000 counted at the last census ( 7 August 2001). Most motorised trips in Melbourne are made by private vehicle with public transport making up only $9 \%$ of all trips. ${ }^{25}$

The sample comprised 4005 people from 50 census collector districts (CCDs) (median number per CCD 47, range 10-92) selected by a two stage sample design who were sent a postal survey about physical activity. A CCD is the basic geographical unit used by the Australian Bureau of Statistics (ABS) to collect population census data. ${ }^{26}$ The CCDs in the study area had an average of 557 residents and a mean size of $0.34 \mathrm{~km}^{2}$ and are similar in population size to enumeration districts in the $\mathrm{UK}^{27}$ and are slightly larger in terms of population size than US census blocks but smaller than census tracts. ${ }^{28}$ Because they are smallest geographical unit for which census data are reported this means that they are also the most homogenous spatial unit with respect to socioeconomic characteristics; however they are not equivalent to output areas in the UK that are constructed after census data are collected to build homogeneous spatial units. ${ }^{27}$

All CCDs in the study area were stratified into septiles using the percentage of households with income of less than $\$ 400$ per week. (This figure was based on consultation with key people in Australia working on area socioeconomic disadvantage and health and it includes 15\% of Australian households (the next ABS income band had 25\% of households making it a less sensitive indicator of very low income households) (John Glover, The Public Health Information and Development Unit, University of Adelaide, personal communication). Most Australian research on area socioeconomic disadvantage uses the index of relative socioeconomic disadvantage (IRSD) for areas, which is developed by the Australian Bureau of Statistics using principal components analysis; the variables that loaded highly on this index are related to education, some occupations, and income. ${ }^{29}$ However, at the time of this sampling for this study, although the 2001 census had been conducted, the IRSD index had not been derived and the 1996 index was considered to be too out of date. Furthermore, studies that have used both percentage of households on low income and the IRSD to examine area socioeconomic disadvantage and health have shown that they produce similar results. ${ }^{30} 31$

As previous multilevel Australian research of food purchasing behaviour ${ }^{32}$ had failed to show statistically significant area variation, we chose to maximise socioeconomic variation, and increase our power to describe statistically significant fixed and random area effects, by randomly selecting 50 CCDs from the upper (17), middle (16), and lower (17) septiles.

Using the electoral roll (voting is compulsory for Australian citizens), 4005 households were randomly selected and then one adult aged 18 to 74 years was randomly selected from each of these households. Up to five contacts were made with respondents including a pre-survey introductory letter, the survey with an incentive enclosed (movie ticket), a thank you postcard, a reminder letter, and another copy of the survey and a final reminder letter to non-responders. ${ }^{33}$ Valid responses were obtained from 2349 persons giving a response rate of $58.7 \%$ (55.1\% from men and $61.8 \%$ from women). Table 1 shows characteristics of the strata and response rates.

Participation rates were inversely associated with area disadvantage, with high SES strata areas having higher rates than mid and low SES strata areas. Compared with census data of our CCDS, our sample had a lower proportion of: households in the lowest quintile of income, persons with no post-school qualification, blue collar workers, men, and persons aged 18 to 24 years (data not shown).

\section{Outcome variables}

Overall levels of physical activity were assessed using items from the Active Australia Survey (AAS). The Active Australia Survey has good reliability and validity and has been used in national surveys. When tested in the Australian population the Active Australia questionnaire has good test-retest reliability achieving slightly higher $\kappa$ values than the Centre for Disease Control Behavioural Risk Factor Surveillance System (BRFSS). and the International Physical Activity Questionnaire-Short Form (IPAQ-S). Correlations between the surveys and measures of accelerometer outputs were similar for the Active Australia, BRFSS and IPAQ-S ( $\rho 0.22-$ 0.25 ) but were less than for the IPAQ-long form ( $\rho 0.36)$, which has more domains of physical activity. ${ }^{34-36}$

Respondents were asked to report the number of occasions (frequency) and estimated time spent (duration) in walking, vigorous garden or yard work, other moderate intensity activity, and vigorous physical activity over the past week. Responses to questions were converted to total amount of time (minutes) doing each activity and were summed, with vigorous activity weighted by a factor of two. ${ }^{36}{ }^{37}$ Participation in less than 150 minutes of activity during the previous week was classified as insufficiently active for health benefit and participation in at least 150 minutes of activity over the previous week was classified as sufficiently active based on the National Physical Activity guidelines that recommend at

Table 1 Details of sampling frame and response rates

\begin{tabular}{|c|c|c|c|c|c|}
\hline & $\begin{array}{l}\text { Number } \\
\text { of CCDs }\end{array}$ & $\begin{array}{l}\text { Low income households } \\
\text { Mean (range) }\end{array}$ & $\begin{array}{l}\text { Adults } \\
\text { sampled (n) }\end{array}$ & $\begin{array}{l}\text { Response rate } \\
\text { (\%) }\end{array}$ & $\begin{array}{l}\text { Final } \\
\text { sample size }\end{array}$ \\
\hline Stratum 1 (high SES) & 17 & $7.0(3.5-8.5)$ & 1355 & 62.1 & 842 \\
\hline Stratum 4 (mid SES) & 16 & $15.3(14.3-16.7)$ & 1347 & 59.0 & 795 \\
\hline Stratum 7 (low SES) & 17 & $31.4(24.1-59.6)$ & 1303 & 54.6 & 712 \\
\hline Total & 50 & $17.8(3.5-59.6)$ & 4005 & 58.7 & 2349 \\
\hline
\end{tabular}


Table 2 Sociodemographic characteristics and physical activity outcomes according to area level socioeconomic strata

\begin{tabular}{|c|c|c|c|c|c|c|}
\hline & \multicolumn{2}{|c|}{ High SES } & \multicolumn{2}{|c|}{ Middle SES } & \multicolumn{2}{|l|}{ Low SES } \\
\hline & $n=842$ & $\%$ & $n=795$ & $\%$ & $n=712$ & $\%$ \\
\hline \multicolumn{7}{|l|}{ Individual level SES } \\
\hline \multicolumn{7}{|l|}{ Sex } \\
\hline Male & 367 & 43.6 & 341 & 42.9 & 315 & 44.2 \\
\hline Female & 475 & 56.4 & 454 & 57.1 & 397 & 55.8 \\
\hline \multicolumn{7}{|l|}{ Age (years) } \\
\hline $18-24$ & 63 & 7.5 & 65 & 8.2 & 58 & 8.2 \\
\hline $25-34$ & 118 & 14.0 & 172 & 21.6 & 126 & 17.7 \\
\hline $35-44$ & 169 & 20.1 & 166 & 20.9 & 165 & 23.2 \\
\hline $45-54$ & 210 & 24.9 & 153 & 19.3 & 135 & 19.0 \\
\hline $55-64$ & 172 & 20.4 & 127 & 16.0 & 94 & 13.2 \\
\hline Over 65 & 110 & 13.1 & 112 & 14.1 & 134 & 18.8 \\
\hline \multicolumn{7}{|l|}{ Occupation } \\
\hline Professionals & 365 & 43.4 & 300 & 37.7 & 178 & 25.0 \\
\hline White collar & 134 & 15.9 & 129 & 16.2 & 115 & 16.2 \\
\hline Blue collar & 68 & 8.1 & 111 & 14.0 & 100 & 14.0 \\
\hline Not in labour force & 262 & 31.1 & 242 & 30.4 & 300 & 42.1 \\
\hline Missing* & 13 & 1.5 & 13 & 1.6 & 19 & 2.7 \\
\hline \multicolumn{7}{|l|}{ Education } \\
\hline Bachelor degree or higher & 325 & 38.6 & 264 & 33.2 & 150 & 21.1 \\
\hline Diploma & 103 & 12.2 & 76 & 9.6 & 83 & 11.7 \\
\hline Vocational & 141 & 16.8 & 152 & 19.1 & 146 & 20.5 \\
\hline No post-school qualifications & 255 & 30.3 & 277 & 34.8 & 308 & 43.3 \\
\hline Missingt & 18 & 2.1 & 26 & 3.3 & 25 & 3.5 \\
\hline \multicolumn{7}{|l|}{ Household income } \\
\hline Aus $\$ 20799$ or less & 40 & 4.8 & 76 & 9.6 & 152 & 21.4 \\
\hline$\$ 20800-\$ 36399$ & 76 & 9.0 & 107 & 13.5 & 92 & 12.9 \\
\hline$\$ 36400-\$ 51999$ & 82 & 9.7 & 95 & 12.0 & 98 & 13.8 \\
\hline$\$ 52000-\$ 77999$ & 103 & 12.2 & 131 & 16.5 & 99 & 13.9 \\
\hline$\$ 78000$ or more & 262 & 31.1 & 166 & 20.9 & 89 & 12.5 \\
\hline Not answered & 279 & 33.1 & 220 & 27.7 & 182 & 25.6 \\
\hline \multicolumn{7}{|l|}{ Outcome variables } \\
\hline \multicolumn{7}{|l|}{ Overall physical activity } \\
\hline Sufficient & 505 & 60.0 & 429 & 54.0 & 330 & 46.4 \\
\hline Insufficient & 320 & 38.0 & 350 & 44.0 & 351 & 49.3 \\
\hline Missing & 17 & 2.0 & 16 & 2.0 & 31 & 4.4 \\
\hline \multicolumn{7}{|l|}{ Walking in the past month } \\
\hline $0-2$ month & 169 & 20.1 & 143 & 18.0 & 141 & 19.8 \\
\hline 1-7 week & 670 & 79.6 & 651 & 81.9 & 567 & 79.6 \\
\hline Missing & 3 & 0.4 & 1 & 0.1 & 4 & 0.6 \\
\hline \multicolumn{7}{|l|}{ Cycling in the past month } \\
\hline No & 677 & 80.4 & 627 & 78.9 & 586 & 82.3 \\
\hline Yes & 158 & 18.8 & 155 & 19.5 & 104 & 14.6 \\
\hline Missing & 7 & 0.8 & 13 & 1.6 & 22 & 3.1 \\
\hline \multicolumn{7}{|l|}{ Jogging in the past month } \\
\hline No & 678 & 80.5 & 655 & 82.4 & 599 & 84.1 \\
\hline Yes & 156 & 18.5 & 136 & 17.1 & 101 & 14.2 \\
\hline Missing & 8 & 1.0 & 4 & 0.5 & 12 & 1.7 \\
\hline \multicolumn{7}{|l|}{ Swimming in the past month } \\
\hline No & 706 & 83.9 & 656 & 82.5 & 601 & 84.4 \\
\hline Yes & 126 & 15.0 & 129 & 16.2 & 100 & 14.0 \\
\hline Missing & 10 & 1.2 & 10 & 1.3 & 11 & 1.5 \\
\hline
\end{tabular}

least 30 minutes of moderate intensity physical activity on most days of the week. ${ }^{38}$

Participation in four common physical activities (walking, cycling, jogging, and swimming $)^{39}$ was also assessed by four closed response items developed for the survey that asked "How often in the last month did you go walking/cycling/ jogging/swimming for 10 minutes or more?". The respondents were asked to nominate one of six responses ranging from never to daily. Pilot testing of these questions showed acceptable test-retest reliability with high levels of agreement on the walking $(\kappa=0.62)$, jogging $(\kappa=0.79)$, and swimming items $(\kappa=0.63)$ and almost perfect agreement on the cycling item $(\kappa=0.85)$. As participation in cycling, jogging, and swimming items were only reported by between $15 \%$ and $18 \%$ of respondents, they were recoded into binary outcomes: "never" (which was coded as zero) or "at least once in the last month", which was coded as 1. For this analysis we also coded walking as a binary outcome with the two least frequent groups "zero or two times a month" coded as zero and all other groups (equivalent to a category of " $1-7$ times per week") coded as l. For overall physical activity being "insufficiently active for health" was coded as zero and being "sufficiently active for health" was coded as 1 .

\section{Area level socioeconomic disadvantage}

Area level socioeconomic disadvantage was categorised as high, medium, or low SES stratum according to the septile from which the CCD was sampled (see table 1 for strata information). The mean proportion of households on low income ranged from $7.0 \%$ in the most advantaged strata to $31.4 \%$ in the most disadvantaged strata.

\section{Individual level variables}

Information on age and sex were obtained from the survey responses or from the electoral roll data if these items were missing. Age was classified into six categories (18-24, 25-34, $35-44,45-54,55-64$, and $\geqslant 65$ years ). 
Occupation was coded to the Australian Standard Classification of Occupations (ASCO) ${ }^{40}$ which groups occupations requiring similar levels of education, knowledge, responsibility, on the job training, and experience. Occupation was then recoded into professionals (managers, administrators, professionals, and paraprofessionals), white collar employees (clerks, salespersons, and service workers) and blue collar employees (tradespersons, machine operator, drivers, labourers, and related workers). A fourth category "not working" was created for respondents who were retired, studying, unemployed, not looking for work, or unable to work.

Respondents were asked to provide their highest school level completed and whether they had completed further education since school. Responses were recoded to the highest education level completed within groupings of (1) bachelor degree or higher, (2) diploma (associate or undergraduate) (3) vocational and (4) no post-school qualification.

The household income item comprised 14 income categories and respondents were asked to provide an estimate of the total before tax household income. Household income was recoded into categories of (1) less than \$20800 (2) \$20 800-36 399 (3) \$36 400-51 999 (4) \$52 000-77 999 and (5) $\$ 78,000$ or more. Households in categories 1 and 2 earned an income at or below the Australian average income and households in categories 3, 4, and 5 earned an income above the average for the 2000-2001 financial year. ${ }^{41}$

Categories for missing responses were also fitted for occupation, income, and education but are not reported in this paper.

\section{Analysis and modelling strategy}

As the outcome variables are binary we performed logistic multilevel analyses using the logit-link function. ${ }^{42}$ Models were fitted using MLwiN version 2.0 using 2nd order PQL estimation methods. ${ }^{43}$ We allowed for extrabinomial variation at level 1 because models showed some evidence of underdispersion. When fitting categorical variables the most frequent category was used as the baseline. Results are presented as odds ratios with $95 \%$ confidence intervals and a $5 \%$ significance level is used. The significance of level 2 variance was tested using "Wald like" statistics and the p values are based on a $\chi^{2}$ distribution. ${ }^{43}{ }^{44}$

To estimate between area variation, we first fitted a two level random intercept model adjusted for age and sex. Secondly, we added individual SES measures (income, occupation, and education) to these models. Thirdly, we included area level socioeconomic disadvantage (with age and sex) to assess the effect of area level socioeconomic disadvantage before adjustment for individual SES. Finally,

Table 3 Multilevel logistic regression models of area SES (strata) and overall physical activity, walking, cycling, jogging, and swimming with and without adjustment for individual SES (income, occupation, education)

\begin{tabular}{|c|c|c|c|c|c|c|c|c|c|c|}
\hline & \multicolumn{2}{|c|}{ Overall physical activity } & \multicolumn{2}{|c|}{ Walking } & \multicolumn{2}{|c|}{ Cycling } & \multicolumn{2}{|c|}{ Jogging } & \multicolumn{2}{|c|}{ Swimming } \\
\hline & OR & $95 \% \mathrm{Cl}$ & OR & $95 \% \mathrm{Cl}$ & OR & $95 \% \mathrm{Cl}$ & OR & $95 \% \mathrm{Cl}$ & OR & $95 \% \mathrm{Cl}$ \\
\hline \multicolumn{11}{|l|}{ Model 1} \\
\hline \multicolumn{11}{|l|}{ Age (years) } \\
\hline $18-24$ & 1.44 & $1.02,2.03$ & 1.46 & $0.97,2.22$ & 1.27 & $0.89,1.82$ & 2.96 & $2.20,3.97$ & 1.14 & $0.75,1.73$ \\
\hline $25-34$ & 1.35 & $1.04,1.76$ & 1.27 & $0.93,1.73$ & 1.16 & $0.88,1.54$ & 1.53 & $1.18,1.99$ & 1.10 & $0.79,1.54$ \\
\hline $35-44$ & 1.0 & & 1.0 & & 1.0 & & 1.0 & & 1.0 & \\
\hline $45-54$ & 1.18 & $0.92,1.51$ & 1.38 & $1.03,1.85$ & 0.75 & $0.56,1.01$ & 0.55 & $0.39,0.78$ & 0.99 & $0.71,1.37$ \\
\hline $55-64$ & 1.28 & $0.98,1.67$ & 1.38 & $1.00,1.90$ & 0.55 & $0.38,0.79$ & 0.37 & $0.23,0.60$ & 0.80 & $0.54,1.17$ \\
\hline$>65$ & 1.25 & $0.94,1.65$ & 1.41 & $1.00,1.99$ & 0.37 & $0.23,0.61$ & 0.18 & $0.07,0.43$ & 0.59 & $0.36,0.94$ \\
\hline \multicolumn{11}{|l|}{ Sex } \\
\hline Female & 1.0 & & 1.0 & & 1.0 & & 1.0 & & 1.0 & \\
\hline Male & 1.03 & $0.87,1.21$ & 0.70 & $0.57,0.86$ & 2.30 & $1.85,2.85$ & 1.57 & $1.28,1.92$ & 0.92 & $0.73,1.15$ \\
\hline Level 2 variance (SE) & \multicolumn{2}{|c|}{$0.127(0.043)$} & \multicolumn{2}{|c|}{$0.242(0.079)$} & \multicolumn{2}{|c|}{$0.226(0.073)$} & \multicolumn{2}{|c|}{$0.159(0.058)$} & \multicolumn{2}{|c|}{$0.142(0.061)$} \\
\hline \multicolumn{11}{|l|}{ Model 2} \\
\hline \multicolumn{11}{|l|}{ Household income } \\
\hline$\$ 78000$ or more & 1.0 & & 1.0 & & 1.0 & & 1.0 & & & \\
\hline$\$ 52000-\$ 77999$ & 0.64 & $0.48,0.86$ & 1.07 & $0.74,1.56$ & 0.83 & $0.61,1.13$ & 0.56 & $0.40,0.78$ & 1.06 & $0.76,1.48$ \\
\hline$\$ 36400-\$ 51999$ & 0.84 & $0.61,1.15$ & 0.96 & $0.65,1.41$ & 0.76 & $0.54,1.09$ & 0.77 & $0.55,1.08$ & 0.85 & $0.56,1.27$ \\
\hline$\$ 20800-\$ 36399$ & 0.56 & $0.40,0.77$ & 0.69 & $0.47,0.99$ & 0.58 & $0.37,0.90$ & 0.59 & $0.39,0.90$ & 0.70 & $0.43,1.15$ \\
\hline$\$ 20799$ or less & 0.56 & $0.39,0.79$ & 0.62 & $0.42,0.93$ & 0.65 & $0.39,1.06$ & 0.58 & $0.35,0.96$ & 0.95 & $0.58,1.54$ \\
\hline \multicolumn{11}{|l|}{ Occupation } \\
\hline Professionals & 1.0 & & 1.0 & & 1.0 & & 1.0 & & 1.0 & \\
\hline White collar & 0.95 & $0.72,1.24$ & 1.08 & $0.76,1.53$ & 0.90 & $0.65,1.26$ & 0.87 & $0.64,1.19$ & 0.71 & $0.49,1.03$ \\
\hline Blue collar & 0.63 & $0.46,0.86$ & 0.68 & $0.49,0.95$ & 0.99 & $0.71,1.38$ & 0.67 & $0.45,0.98$ & 0.73 & $0.47,1.15$ \\
\hline Not in labour force & 0.83 & $0.64,1.08$ & 1.12 & $0.81,1.57$ & 0.79 & $0.56,1.11$ & 0.70 & $0.50,0.97$ & 0.80 & $0.57,1.13$ \\
\hline \multicolumn{11}{|l|}{ Education } \\
\hline Bachelor or higher & 1.36 & $1.07,1.72$ & 1.04 & $0.78,1.40$ & 1.39 & $1.03,1.87$ & 1.25 & $0.95,1.66$ & 1.33 & $0.96,1.83$ \\
\hline Diploma & 1.31 & $0.98,1.76$ & 1.71 & $1.10,2.67$ & 1.30 & $0.89,1.88$ & 0.87 & $0.59,1.29$ & 1.14 & $0.75,1.74$ \\
\hline Vocational & 1.28 & $1.01,1.63$ & 0.99 & $0.76,1.29$ & 1.41 & $1.04,1.90$ & 0.84 & $0.60,1.17$ & 1.26 & $0.88,1.79$ \\
\hline No post-school qual & 1.0 & & 1.0 & & 1.0 & & 1.0 & & 1.0 & \\
\hline Level 2 variance (SE) & \multicolumn{2}{|c|}{$0.046(0.027)$} & \multicolumn{2}{|c|}{$0.209(0.071)$} & \multicolumn{2}{|c|}{$0.201(0.067)$} & \multicolumn{2}{|c|}{$0.054(0.037)$} & \multicolumn{2}{|c|}{$0.127(0.058)$} \\
\hline Model 3 & & & & & & & & & & \\
\hline Strata & & & & & & & & & & \\
\hline High & 1.0 & & 1.0 & & 1.0 & & 1.0 & & 1.0 & \\
\hline Medium & 0.79 & $0.59,1.05$ & 1.14 & $0.74,1.78$ & 0.97 & $0.66,1.44$ & 0.77 & $0.55,1.07$ & 1.16 & $0.80,1.68$ \\
\hline Low & 0.59 & $0.45,0.79$ & 0.95 & $0.62,1.45$ & 0.71 & $0.47,1.07$ & 0.58 & $0.41,0.82$ & 0.97 & $0.66,1.43$ \\
\hline Level 2 variance (SE) & 0.084 & & 0.239 & & 0.205 & & 0.113 & & 0.136 & \\
\hline Model 4 & & & & & & & & & & \\
\hline Strata & & & & & & & & & & \\
\hline High & 1.0 & & 1.0 & & 1.0 & & 1.0 & & 1.0 & \\
\hline Medium & 0.85 & $0.67,1.08$ & 1.25 & $0.82,1.90$ & 1.04 & $0.71,1.54$ & 0.82 & $0.62,1.08$ & 1.18 & $0.81,1.73$ \\
\hline Low & 0.70 & $0.55,0.90$ & 1.03 & $0.69,1.55$ & 0.84 & $0.56,1.26$ & 0.69 & $0.51,0.94$ & 1.07 & $0.72,1.59$ \\
\hline Level 2 variance (SE) & 0.030 & & 0.201 & & 0.194 & & 0.141 & & 0.136 & \\
\hline
\end{tabular}


we tested a model including all level 1 fixed effects and the socioeconomic strata at level 2.

\section{RESULTS}

Table 2 presents the distribution of the independent variables and physical activity outcomes by area level SES. Respondents from low SES areas reported more frequently that they were of low education, low household income, worked in lower skilled jobs, or did not work, than did respondents from high SES areas. A higher proportion of respondents from low SES areas had overall physical activity levels that were insufficiently active for health than respondents from high SES areas. Walking was the most common activity with around $80 \%$ of respondents reporting they walked between one to seven times per week.

Table 3 presents the results of the multilevel analysis for the overall physical activity, walking, cycling, jogging, and swimming outcomes.

\section{Overall physical activity}

After adjusting for age and sex there were significant area differences in levels of overall physical activity (model 1) $(p=0.004)$. Inclusion of individual SES and socioeconomic strata reduced the area level variance, however, people living in low socioeconomic strata areas were less likely to have overall physical activity levels that were sufficiently active for health, even after adjustment for individual SES (OR 0.70, $95 \%$ CI 0.55 to 0.90$)$.

\section{Walking}

Area level variation in walking was seen after adjustment for age and sex (model 1$)(\mathrm{p}=0.002)$, individual SES (model 2) $(p=0.004)$, area level socioeconomic strata (model 3$)$ $(\mathrm{p}=0.002)$, and strata and individual SES combined (model 4) $(p=0.004)$. Area level socioeconomic stratum was not associated with the likelihood of walking.

\section{Cycling}

Area level variation in cycling was seen after adjustment for age and sex (model 1) ( $\mathrm{p}=0.002)$, individual SES (model 2) $(\mathrm{p}=0.003)$, area level socioeconomic stratum (model 3$)$ $(p=0.003)$, and stratum and individual SES combined (model 4) $(\mathrm{p}=0.003)$. Area level socioeconomic disadvantage was not associated with likelihood of cycling.

\section{Jogging}

Area level variation in jogging was seen after adjustment for age and sex (model 1$)(p=0.007)$ but became weaker when adjusted for individual SES. Living in a low socioeconomic areas was associated with less likelihood of jogging $(\mathrm{OR}=$ $0.58,95 \%$ CI 0.41 to 0.83 ), an effect that was attenuated only slightly when adjusted for individual SES (OR $=0.69,95 \% \mathrm{CI}$ 0.51 to 0.94 )

\section{Swimming}

Area level variation was seen when age and sex were included in the model (model $1, p=0.021$ ), individual SES (model 2) $(\mathrm{p}=0.028)$, area level socioeconomic stratum (model 3) $(\mathrm{p}=0.024)$, and stratum and individual SES combined (model 4) $(\mathrm{p}=0.031)$. Area level socioeconomic stratum was not associated with swimming.

\section{DISCUSSION}

We have shown variation between small areas in the propensity of people to walk, cycle, swim, jog, and overall levels of physical activity. For walking, cycling, and swimming this variation is independent of individual SES and area level socioeconomic disadvantage. Living in areas that are more socioeconomically disadvantaged is associated with less

\section{What this paper adds}

This paper substantiates the claim that local environments are important determinants of physical activity participation. This is the first Australian multilevel study of physical activity participation and, consistent with international evidence, it shows that residing in socioeconomically disadvantaged areas affects overall levels of physical activity participation. It is the first international study (that we know of) that has reported significant between area variation in participation in walking, cycling, and swimming. Future studies must address what characteristics of the local environment drive the between area differences in physical activity participation.

likelihood of having overall physical activity levels that are sufficiently active for health or jogging, effects that persisted even after adjustment for individual SES and area level socioeconomic disadvantage.

This study is consistent with other evidence that shows that living in socioeconomically disadvantaged areas is associated with lower levels of overall physical activity participation. The physical activity measure used in this study is a composite measure of walking, vigorous garden or yard work, other moderate intensity activity, and vigorous physical activity. It is possible that area level socioeconomic disadvantage has a differential impact on the different components of this measure. By examining four specific physical activity behaviours we were able to examine this more thoroughly and, as described, there is support for the possibility that area level disadvantage is associated with a reduced likelihood of jogging. This suggests that the characteristics of socioeconomically disadvantaged areas may make them less conducive to jogging (and possibly outdoor activity more generally) than more advantaged areas.

The area level differences in walking, cycling, and swimming point to the possibility that there are clear area level characteristics that facilitate these activities. However, these characteristics do not seem to be stratified according to area level socioeconomic characteristics. None the less, the fact that we do find significant area level variation suggests the existence of important area level characteristics. If these characteristics can be identified, area level interventions, such as improved cycling and walking paths and swimming pools, might be implemented to increase the incidence of walking, cycling, and swimming.

Future work should be aimed at collecting detailed environmental data that could plausibly explain these findings including details about the presence and quality of footpaths, walking, cycling and jogging trails, lighting, surveillance from nearby buildings and houses, land use, location of shops and other facilities, parks, waterfronts, aesthetics, and access and quality of public swimming pools. Key characteristics that contribute to area level differences could guide future urban planning activities. However, based

\section{Policy implications}

This study underscores the need to consider urban planning initiatives to improve physical activity participation. Such initiatives are likely to improve population based physical activity levels although they may not make substantial differences at the individual level. 
on the limited evidence reported to date, engineering changes, such as the extension of cycle paths, have not generally resulted in positive changes in the relative proportions of commuting that occurs by car or by bicycle or walking. ${ }^{45}$ None the less the interventions and evaluations that have thus far been conducted have been comparatively limited and it is possible that identifying more specific environmental characteristics may permit the development of more appropriately targeted interventions. For example, there is promising early evidence from the UK National Cycling Network initiative, which has involved developing a comprehensive network of safe and attractive places to walk and cycle, where the number of cycle trips on the network increased by $10 \%$ in one year. ${ }^{46}$

By sampling areas from the upper, middle, and lower septiles of socioeconomic disadvantage, we maximised socioeconomic variability and therefore increased the possibility that we could describe differences between the area level socioeconomic strata. However, cycling, jogging, and swimming are comparatively low frequency activities, and this limits our power to find potentially important effects, although, provided there are sufficient numbers of people in each higher level unit, multilevel studies tend to have more power to detect fixed effects of area variables than they do to detect significant between area variation. ${ }^{47}$

We included three measures of individual SES in our models. This reduces the likelihood that the effects of area socioeconomic disadvantage are attributable to unmeasured or poorly measured confounding by individual SES. ${ }^{47-49}$ However, it is possible that there is over-adjustment as some of the individual variables may lie on the causal pathway between the area level socioeconomic disadvantage and physical activity. Including models with area level socioeconomic disadvantage before and after adjustment for individual SES provides an interval estimate of the likely effect of area level socioeconomic disadvantage. ${ }^{49}$

Both walking and cycling can be undertaken for transportation (for example, shopping) or for exercise, or both, and it is probable the determinants of these may vary. For example, high quality walking paths in parklands may be an important determinant of walking for exercise while the quality of local footpaths may affect the likelihood that people will walk for transportation. However, while in our survey we are unable to determine the exact frequency of these activities for transportation or exercise, only $17 \%$ of people who walked at least once a week and 9\% of people who cycled at least once a month did that solely for transportation.

We achieved a moderate response rate of 59\% and consistent with previous studies, ${ }^{50}$ our response was lowest in the lowest SES stratum areas. It is not possible to know whether the movie ticket incentive biased our participation rates towards low or high SES groups. While the cinema chain we chose had comprehensive geographical coverage it is possible that the low SES groups may have found the incentive less useful because they were less likely to be able to travel by car (the proportion of households without a car ranged from $5.4 \%$ in the high SES stratum areas to $22.1 \%$ in the low stratum areas). However, it is also possible low SES may value a movie incentive more because of limited financial resources. None the less, the lower participation rates by low SES groups may result in an underestimation of the true magnitude of SES differences because of an underrepresentation of the low SES people who are least likely to participate in physical activity. Non-response bias is also more likely in men than women because of the lower participation rates among men.

In summary, this study provides the first known evidence of significant area level differences in walking, cycling, and swimming. Furthermore, it confirms previous studies that show effects of area level socioeconomic disadvantage on overall physical activity levels and jogging. Future work should concentrate on identifying environmental characteristics that might explain these differences so that interventions can be appropriately targeted. However, we also recommend the continuation, or expansion, of individually based health promotion activities to improve physical activity, particularly among low SES groups, because the evidence to date suggests that individual attributes such as knowledge and motivation are key determinants of physical activity participation.

\section{ACKNOWLEDGEMENTS}

We are grateful to all the staff that contributed to the distribution of the survey and are particularly grateful to Ms Emma Rawlings and Mr Lukar Thornton who were responsible for managing the survey distribution and data entry.

\section{Authors' affiliations}

A M Kavanagh, J L Goller, T King, Australian Research Centre in Sex, Health and Society, La Trobe University, Melbourne, Australia A M Kavanagh, T King, Key Centre for Women's Health in Society, School of Population Health, University of Melbourne, Melbourne, Australia

J L Goller, Department of Human Services, Victoria, Australia D Jolley, Monash Institute of Health Services Research, Monash University, Melbourne, Australia

D Crawford, Centre for Physical Activity and Nutrition Research School Exercise and Nutrition Sciences, Deakin University, Victoria, Australia G Turrell, School of Public Health, Queensland University of Technology, Brisbane, Australia

Funding: the first author is supported by a Victorian Health Promotion Foundation (VicHealth) Senior Research Fellowship. The fifth and sixth author are supported by a National Health and Medical Research Council/National Heart Foundation Career Development Awards (187028 and CR 01B 0502). The project was funded by the Victorian Health Promotion Foundation.

Conflicts of interest: none.

Ethics approval: the project was approved by the La Trobe University Human Ethics Committee.

\section{REFERENCES}

1 Pate RR, Pratt M, Blair SN, et al. Physical activity and public health: a recommendation from the Centers for Disease Control and Prevention and the American College of Sports Medicine. JAMA 1995;273:402-7.

2 World Health Organisation. The world health report: 2004: changing history. Geneva: World Health Organisation, 2004

3 Mathers C, Vos T, Stevenson C. The burden of disease and injury in Australia: AlHW catalogue no PHE 17. Canberra: Australian Institute of Health and Welfare, 1999.

4 Burton N, Payeh M, Turrell G. Occupation, hours worked, and leisure-time physical activity. Prev Med 2000;31:673-81.

5 Crespo CJ, Ainsworth BE, Keteyian SJ, et al. Prevalence of physical inactivity and its relation to social class in US adults: results from the third national health and nutrition examination Survey, 1988-1994. Med Sci Sports Exerc 1999:31:1821-7.

6 Department of Human Services. Victorian population health survey 2003: rural and regional health and aged care services. Melbourne, Victoria: Victorian Government Department of Human Services, 2004.

7 Owen N, Leslie E, Salmon J, et al. Environmental determinants of physical activity and sedentary behavior. Exer Sport Sci Rev 2000;28:153-8.

8 Owen N, Humpel N, Leslie E, et al. Understanding environmental influences on walking; review and research agenda. Am J Prev Med 2004;27:67-76.

9 Giles-Corti B, Donovan R. Socioeconomic status difference in recreational physical activity levels and real and perceived access to a supportive physical environment. Prev Med 2002;35:601-12.

10 Ball K, Bauman A, Leslie E, et al. Perceived environmental aesthetics and convenience and company are associated with walking for exercise among Australian adults. Prev Med 2001;33:434-40

11 Giles-Corti B, Broomhall M, Knuiman M, et al. Increasing walking-How important is distance to, attractiveness, and size of public open space? Am J Prev Med 2005;28:169-76.

12 Powell K, Martin L, Chowdhury P. Places to walk: convenience and regular physical activity. Am J Public Health 2003;93:1519-21. 
13 Bauman A, Smith B, Stoker L, et al. Geographical influences upon physical activity participation: evidence of a 'coastal' effect. Aust N Z J Public Health 1999;23:322-4.

14 Saelens BE, Sallis J, Frank LD. Environmental correlates of walking and cycling: findings from the transportation, urban design and planning literature. Ann Behav Med 2003;25:80-91.

15 Frank L, Schmid T, Sallis J, et al. Linking objectively measured physical activity with objectively measured urban form-findings from SMARTRAQ. Am J Prev Med 2005;28:117-25.

16 Addy C, Wilson D, Kitland K, et al. Associations of perceived social and physical environment supports with physical activity and walking behavior. Am J Public Health 2004;94:440-3.

17 Giles-Corti B, Donovan R. Relative influences of individual, social environmental and physical environmental correlates of walking. Am J Public Health 2003;93:1583-9.

18 Huston S, Evenson K, Bors P, et al. Neighbourhood environment, access to place for activity, and leisure-time physical activity in a diverse North Carolina population. Am J Health Prom 2003; 18:58-69.

19 Fuzhong L, Fisher K, Bauman A, et al. Neighbourhood influences on physical activity. J Aging Phys Activity 2005;13:87-114.

20 Yen IH, Kaplan GA. Poverty area residence and changes in physical activity level: evidence from the Alameda County study. Am J Public Health 1998;88:1709-12.

21 Sundquist J, Malmstrom M, Johansson SE. Cardiovascular risk factors and the neighbourhood environment: a multilevel analysis. Int J Epidemiol 1999;28:841-5.

22 van Lenthe F, Brug J, Mackenback J. Neighbourhood inequalities in physical inactivity: the role of neighbourhood attractiveness, proximity to local facilities and safety in the Netherlands. Soc Sci Med 2005;60:763-75.

23 Wendel-Vos G, Schutt A, De Neit R, et al. Factors of the physical environment associated with walking and bicycling. Med Sci Sports Exer 2004;36:725-30.

24 Ross C. Walking, exercising, and smoking: does neighborhood matter? Soc Sci Med 2000;51:265-74

25 Department of Sustainability and Environment. Melbourne 2030: planning for sustainable growth. Melbourne: Victorian State Government, 2002.

26 Australian Bureau of Statistics. 2001 Census of population and housing: how Australia takes a census. Canberra: Australian Bureau of Statistics, 2000

27 Martin D. Optimizing census geography: the separation of collection and output geographies. International Journal of Information Science 1998; 12:673-85.

28 Bureau of Statistics. Geographic areas reference manual. Washington: US Department of Commerce, 1994.

29 Australian Bureau of Statistics. Census of population and housing: socioeconomic indexes for area's (SEIFA). Canberra: ABS, 2004.

30 Public Health Information and Development Unit. Social health atlas of Australia. Adelaide: Open Book Publishers, 1999.
31 Turrell G, Mengersen K. Socioeconomic status and infant mortality in Australia: a national study of small urban areas, 1985-89. Soc Sci Med 2000;50:1209-25

32 Turrell G, Blakely T, Patterson C, et al. A multilevel analysis of socioeconomic (small area) differences in household food purchasing behaviour. J Epidemiol Community Health 2004;58:208-15.

33 Dillman DA. Mail and internet surveys: the tailored design method. 2nd ed. New York: Wiley, 2000

34 Timperio A, Salmon J, Bull F, et al. Validation of adult physical activity questions for use in Australian population surveys. Canberra: Australian Institute of Health and Aging, 2002.

35 Timperio A, Salmon J, Crawford D. Validity and reliability of a physical activity recall instrument among overweight and non-overweight men and women. J Sci Med Sport 2003;6:477-91.

36 Australian Institute of Health and Welfare. The Active Australia: a guide and manual for implementation, analysis and reporting. Canberra: AlHW, 2003.

37 Armstrong T, Bauman A, Davies J. Physical activity patterns of Australian adults. Results of the 1999 National Physical Activity Survey. Canberra: Australian Institute of Health and Welfare, 2000.

38 Department of Health and Aged Care. National physical activity guidelines for Australians. Canberra: DHAC, 1999.

39 Bull F, Milligian R, Rosenberg M, et al. Physical activity levels of Western Australian adults 1999. Perth: Western Australian Government, 2000.

40 Australian Bureau of Statistics. Australian standard classification of occupations: dictionary. 2nd ed. Canberra: Australian Government Publishing Service, 1997.

41 Australian Bureau of Statistics. Household income and income distribution, Australia 2000-2001. Canberra: Australian Government Publishing Service, 2003.

42 Snijders T, Bosker R. Multilevel analysis. London: Sage, 1999.

43 Rasbash J, Browne W, Goldstein H, et al. A user's guide to MLwiN, version 2.1. London: Institute of Education, University of London, 2000.

44 Goldstein H. Multilevel statistical models. London: Arnold, 2003.

45 Ogilvie D, Egan M, Hamilton V, et al. Promoting walking and cycling as an alternative to using cars: systematic review. BMJ 2004;329:763-6.

46 Sustrans Research and Monitoring Unit. Sustrans: the national cycle network route use monitoring report. Newcastle upon Tyne, UK: Sustrans' Research and Monitoring Unit, 2004.

47 Diez Roux AV. Estimating neighbourhood health effects: the challenges of causal inference in a complex world. Soc Sci Med 2004;58:1953-60.

48 Diez-Roux A. Bringing context back into epidemiology: variables and fallacies in multilevel analysis. Am J Public Health 1998;88:216-22.

49 Blakely T, Woodward A. Ecological effects in multi-level studies. J Epidemiol Community Health 2000;54:367-74.

50 Turrell G. Income non-reporting: implications for health inequalities research. J Epidemiol Community Health 2000;54:166-72. 